\title{
Fire safety issues in the design and construction of high-rise buildings
}

\author{
Tatiana Poliakova ${ }^{1 *}$ and Marina Grigoryan ${ }^{1}$ \\ ${ }^{1}$ DSTU, 344022, Rostov-on-Don, Russia
}

\begin{abstract}
The construction of high-rise buildings has revealed new problems related to fire safety. The peculiarity of the architecture, which is covered in high-rise, in fires creates a danger for a large number of people there, reduces the possibility of their evacuation and rescue. The multifunctionality of such buildings, taking into account the originality of the external and internal views, leads to the difficulty of choosing a constructive system, a large number of utilities and technical systems. To address the issues related to safe operation, stay and evacuation of people is the development of a fire protection system for high-rise buildings, based on the development of:

- measures to ensure the durability of buildings or parts thereof against progressive collapse due to $*$ ensuring the fire resistance of structures and buildings;

- measures to limit the spread of fire in high-rise buildings through the installation of fire barriers inside the building and the device of fire breaks between buildings;

- measures for ensuring timely and unimpeded evacuation of people and their rescue at emergency in high-rise buildings;

- systems of active protection of buildings from fire, namely: fire alarm and fire fighting, strong points of fire extinguishing.
\end{abstract}

\section{Introduction}

Every year in the cities of Russia increases the number of high-rise residential and multipurpose buildings, the height of which exceeds $75 \mathrm{~m} \mathrm{[1].}$

The construction of such buildings revealed new problems related to fire safety. The peculiarity of the architecture, which lies in the increased number of floors, in case of fires, creates a danger for a large number of people there, reduces the possibility of their evacuation and rescue. Multifunctionality of such buildings, taking into account the originality of external and internal views, leads to the complexity of the choice of structural systems, a large number of utilities and technical systems [2].

The high speed of the spread of combustion products leads to the filling of escape routes, and the rapid smoke of the building makes it fatal for people to be in it. 


\section{Statistics}

Statistics on fires in the last century and at the beginning of this, confirm the fact that the fire in high-rise buildings is more dangerous than low-rise buildings.

Here is an incomplete list of the largest fires:

- 28.07.1945 in new York city in a fire in a 102-storey skyscraper "Empire state building" burned from 75-th to 79-th floor;

- $\quad 01.02 .1974$ g. in San Paulo (Brazil) in a fire in the 25-storey "Joelma building" killed 227 people and 450 injured;

- $\quad$ 05.05.1988, in Los Angeles in the 62-storey Bank "First Interstate Bank", a fire engulfed 5 floors, one person was killed, more than 40-were injured;

- $\quad 17.07 .1990$ g. in New York in a fire in the skyscraper "Empire state building", 38 people were injured;

- 25.02.1991 g. fire 38-storey skyscraper in Philadelphia;

- 17.01.1996 a fire in a skyscraper on the 45th floor in the city of London, evacuated about 500 people;

- 18.12.1997 in Jakarta (Indonesia) there was a fire in a 25-storey Bank, three upper floors burned out completely, 15 people were killed;

- 11.09.2001 in New York as a result of terrorist attack there was a fire in a complex of the world trade center, 19 terrorists, 2977 people were lost, 24-were missing;

- May 2006 in Astana (Kazakhstan) fire in the 32-storey "Transpore tower". There were no injuries;

- Vladivostok (Russia) 16.01.2006, a fire in a 9-storey building took the lives of 9 people, 17-injured;

- February 2005. Madrid, the fire in the 106-meter Windsor tower in the business district, there are no victims and this is not a complete list of cases of fires and victims in high-rise buildings of the world [3].

\section{Summary}

If we briefly summarize the analysis of fires in high-rise buildings (in particular, built at the end of the last century), the following circumstances that led to a sad outcome:

- insufficient fire resistance of structures and engineering equipment;

- large internal volumes without separating fire barriers;

- insufficient number of stairwells (also with a small width of the ladder March);

- a large number of openings in the floors and walls (partitions) for various needs (air conditioning, electricity, etc.);

- a lot of flammable equipment, furniture and cladding, as well as suspended ceilings [4].

One of the important issues in the design of high-rise buildings is the correct definition of fire resistance of any building, in the solution of which an important role is played by the limit of fire resistance of structures. The fire resistance limit is the ability of structures (and the building as a whole) in a fire to maintain technical characteristics within a certain period of time for which people will be evacuated from the building. For quantitative characteristics adopted "fire resistance limit" - the time period measured in minutes, from the beginning of the loss of design specifications and to reach the limit States (the appearance of cracks, loss of integrity, bearing and thermal insulation properties) [5].

As in the regulations, all the indicators for the limit of fire resistance of structures are buildings lower than 75 meters, so the limits of fire resistance of structures (load-bearing structures) for high-rise buildings is increased by another hour. However, this way leads to an increase in the volume and mass of building structures, and as a consequence to the rise in the cost of construction and the difficulties not only in the design, but also in construction. In addition, some structures with an unsatisfactory limit of fire resistance need additional 
protection from high temperatures, both structurally and by applying a protective coating on the surface.

In the design, along with the fact that the means are provided for limiting the fire beyond the fire source, are considered and taken to implement the space-planning decisions, which include:

- first, the division of buildings into fire compartments, both vertically and horizontally, while limiting their area and height;

- secondly, the division of the building fire ceilings, walls, partitions, blocking the hearth within the premises or in groups of rooms with different classes of functional fire hazard.

In the design of high-rise buildings in the division into fire compartments vertically used fire ceilings, and horizontally-fire walls. In this functional group must have an independent output and be separated by fire walls and ceilings. It should be taken into account that the minimum allowable area of the fire compartment should be $1500 \mathrm{sq} . \mathrm{m}$., and this entails the breakdown of the floors of high-rise multifunctional buildings on the compartments of no more than 1500 sq. $\mathrm{m}$ [6].

Vertically, it is planned to divide the building into fire compartments:

- by functional groups of spaces;

- every 40 - $50 \mathrm{~m}$, if the height of the groups exceeds $50 \mathrm{~m}$;

- elevator halls are separated from adjacent corridors and rooms by fire partitions.

In high-rise buildings every $50 \mathrm{~m}$ in height for the stay of people during a fire, technical floors are provided, in this capacity can be used and the so-called outrigger floors. Despite the technical purpose, technical floors act as" fire containers", as they are separated by fire ceilings.

The second most important issue in case of fires in high-rise buildings is safe evacuation of people. The movement of people in buildings is of two types: normal and forced (in emergencies). In the second case, the direction of human flow is in the direction of evacuation exits. In emergencies (fire, in particular), the flow density may reach limits that may result in serious injury or even loss of life [7].

In high-rise buildings to the evacuation exits are primarily the exits leading to the outside, outputs to the stairwell, and finally exits on the technical floors if they are "fireproof containers". According to the regulations, in case of fire evacuation in high-rise buildings is provided to carry out a minimum of two smoke-free stairwells type H1. Given the height of the buildings, stairwells and elevator shafts must be divided into compartments every 30 - 50 meters, with the mandatory provision of air backup [8].

In case of fire evacuation, the use of passenger elevators is not possible, as they are often deenergized due to fire. Therefore, when designing high-rise buildings, elevators with special equipment (with a capacity of at least $1000 \mathrm{~kg}$ ) for rescue fire departments should be provided. At the same time, according to the regulatory requirements, the number of fire elevators should be at least two in each vertical compartment, and the entrances to the elevator halls are carried out through the vestibule-locks with mandatory air pressure [9].

When analyzing the causes and course of fires, for example, at the world Trade Center in New York, another problem aspect that requires reflection in the regulations was revealed.

The simultaneous nature of several threats, namely combustion or fire damage of combustible materials and objects, has determined the importance of adequate fire protection. The main methods of fire prevention work to reduce the probability of fire (preventive, passive) and directly protect and save people from fire (active).

Sufficient security leads to the inability to evacuate people. The estimated strength of the metal frame and structural components was sufficient when the aircraft was hit, but the low degree of fire resistance led to fire and destruction. Thus, the solution of one problem entails negative consequences from the other. That is, when solving issues of fire protection, it is necessary to take into account mutually acceptable solutions from other threats. However, unfortunately, there is still not a sufficiently complete list of threats with 
the necessary degree of protection.

The action of flame-retardants is based on the isolation of the protected object from the effects of high temperature.

Typically, such measures do not prevent fire in a fire, but increase the strength of the protected materials in front of the fire. Even the use of steel carriers the structures do not exclude their damage by fire in conditions of long-term exposure high temperature.

In Russia, the level of fire risk (and in particular in high-rise construction) is quite high. Russia lags behind economically developed countries in almost all basic parameters of fire risk, such as the frequency of fires, individual risk, specific damage, etc.

In March 1993, a fire in a 25-storey building in Moscow, on Marshal Zhukov Avenue, killed 5 people. In November 2005, a 25-storey building burned down on the second Setun passage in Moscow: 4 people were killed, 15 were saved. In both cases, the cause of such consequences was the outdated fire protection of buildings.

Moscow is actively engaged in the design and construction of high-rise buildings and multifunctional complexes. This complex "Moscow city "and 60 high-rise buildings under the program "New ring of Moscow".

\section{References}

1. SP 267.1325800.2016 High-rise buildings and complexes high-rise. Design rules

2. T.G. Maklakova, High-rise buildings. Urban planning and architectural and constructive design problems: Monograph. Second edition, supplemented (ASV Publishing House, Moscow, 2008)

3. S.V. Nikolaev, Modern high-rise construction. Monograph (State Unitary Enterprise "ITC Moscomarchitecture", Moscow, 2007)

4. V.A. Kharitonov, Design, construction and operation of high-rise buildings, Monograph (ASV, Moscow, 2014)

5. V.M. Roitman, Basics of fire safety of high-rise buildings (MSSU, Moscow, 2009)

6. L.N. Sedegova, The Eng. H. of the Don, Features of civil construction in the current urban development, 2, 123 (2013)

7. V. V. Kholshchevnikov, Fire and Explosion Safety, Some aspects of securing the safety of evacuation in high-rise buildings, 6, 34 (2006)

8. T. Y. Eremin, I.A. Egorov, Fire Safety, Fire danger of high-rise buildings: evacuation and protection of people from combustion products, 2, 141-146 (2014)

9. S.V. Nikolaev, Modern high-rise construction, Monograph (ITC Moscomarchitecture, Moscow, 2007) 